\title{
Evaluation and Comparison of the Qualitative Properties of Lavash Bread Types during Storage by Different Techniques
}

\author{
Leila Kamali-roosta ${ }^{1}$, Mahdi Seyedian Ardebili ${ }^{* 2}$, Gholam Hasan Asadi ${ }^{2}$, Babak Ghiassi Tarzi ${ }^{2}$, Reza Azizinejad ${ }^{2}$ \\ 1- Ph.D. in Food Science and Technology, Science and Research Branch, Islamic Azad University, Tehran, Iran. \\ 2- Dept. of Food Science and Technology, Science and Research Branch, Islamic Azad University, Tehran, Iran.
}

\section{A B S T R A C T}

Background and Objectives: The quality of flat breads depends in part on their textural and structural properties during storage. These properties are largely affected by flour quality. This research aimed at evaluating the textural and structural properties of Lavash bread types during storage by different techniques, comparing these methods, and determining the possible correlation between the obtained results.

Materials and Methods: Three Lavash flours (named strong, medium and weak flours) with different physical, chemical and rheological properties were used. Determination of texture firmness of Lavash breads (Lavash A, Lavash B and Lavash C made of strong, medium and weak flours, respectively) during storage was carried out by Texture analyzer, evaluation of breads porosity and their changes process during storage was performed by ultrasonic nondestructive technique, assessment of the breads' microstructure was made by SEM, evaluation of starch gelatinization and retro-gradation was performed by DSC, and the sensory evaluation of breads was made by a trained panelist. All determinations were made in triplicate, except the sensory test that was performed in ten repeats, and mean values were presented.

Results: Lavash B made from medium flour had less firmnness, lower transition of ultrasonic wave velocity, less value of elastic modulus, reduced value of enthalpy, lower average temperature, more pore diameter and area of images, and higher points of sensory evaluation than Lavash A and Lavash $\mathrm{C}$ breads during the storage time. The results of mentioned tests (devices and sensory tests) had significant correlation to each other.

Conclusions: Desirable quality characterization and higher shelf life of Lavash B were due to flour qualitative characteristics of this type of bread to obtain dough with appropriate elasticity and excellent sheeting capability. Ultrasonic non-destructive method is recommended to use instead of other methods for assessing texture, cell structure and elastic properties of bread after baking and during the storage time. This method is fast, non-destructive and cheaper than other methods, and can be used during production.

Keywords: Flat bread, Quality, Retro-gradation, Stalling

\section{Introduction}

In general, from physico-mechanical point of view, bread has a composite multiphase structure with high porosity (1-3). Objective evaluation of structural parameters of porous cereal products (including bread) is important in the characterization of sensory properties (4-6). Therefore, porosity is one of the most important quality properties of grain products (7-10). The final crumb structure of bread is critical to consumer acceptance of baked products (10-12).
Thus, knowledge of the structural organization of bread is of critical importance for our understanding of the visual appearance of bread crumb and the concomitant consumer's perception of bread quality. Bread quality decreases during storage because bread crumb and crust get firmed and lose resilience (13). Since mainly starch, protein and water contribute to the structural architecture and the mechanical strength of bread, they are assumed to play an important role 
in the change of textural properties during the bread storage (14). Besides the molecular changes that determine crumb firming, bread firmness itself depends on its density (15). Most anti-firming additives influence not only cell wall constituents such as starch but also they often affect structural properties like cell size and density. Hence, it is necessary to understand the macroscopic behavior and complexity of bread crumb during storage and to relate them to the biopolymer building blocks of bread (13). Evaluation of the mechanical properties of crumb is of particular importance as they determine the consumer's perception of bread quality (16). A number of techniques have been used to measure the mechanical properties of bread crumb, including indentation $(17,18)$, compression (18-20), tension $(5$, 21), and shear measurements (22). In addition, a variety of tests may be used to assess the stalling process of bread and changes in the cellular structure of bread during the storage such as using DSC (Different Scanning Calorimeter) device, image and ultrasonic methods $(23,24)$.

Faergestad et al. (2000) studied the baking performance of hearth bread and pan bread using wheat flours with different protein contents, and showed that effects of flour quality on bread characteristics were different for hearth bread compared to pan bread (25). Elmehdi et al. (2003) used ultrasonic techniques to study how the mechanical properties of bread crumb are affected by changing the size, concentration and shape of the crumb cells. The sensitivity of ultrasonic waves to changes in the size and shape of crumb cells demonstrates the potential for using ultrasound as a tool for characterizing the mechanical and structural properties of bread crumb [11]. Aamodt et al. (2005) studied the effect of protein quality and content on hearth bread characteristics by texture analyzer, and indicated that an increased amount of flour with strong quality improved hearth bread characteristics to a larger extent than increased its protein content, in turn (26). Lagrain et al. (2013) evaluated the role of gluten and starch in crumb structure and texture of fresh and stored straight-dough breads, and showed that changing gluten properties in dough had a profound impact on bread density and its foam structure without affecting the rheological properties of the crumb cell walls (27). Flat breads have been baked and consumed as a staple food for many centuries. More than 60 types of flat breads are made worldwide. In this study, Lavash bread that is one of the most popular flat breads in Iran was evaluated. It is made from Lavash flour along with water, salt and yeast; then it is baked on a hot flat surface (28). Flat breads are baked from dough sheets, which are often 1-3 mm thick. They have a short baking time of about 2-3 minutes (29); thus the impact of flour properties on the end product's characteristics may be different in flat breads compared with pan breads, which bake for longer time and have sufficient time to expand (25). Toufeili et al. (1999) studied the rule of gluten proteins in the baking of Arabic bread, and indicated that highly elastic doughs derived from high quality gluten are not compatible with the rapid expansion of gases under the high temperature - short time conditions employed in the baking of flat breads (30). Salehifar et al. (2010) studied the stalling process of Taftoon bread by texture analyzer, and indicated that high protein flours with strong qualities are not able to sheet and expand during high temperature - short time conditions employed in the baking of Taftoon bread (31).

This research aimed at evaluating the textural and structural properties of Lavash bread types during storage by different techniques, comparing these methods, and determining the correlation between their results. Also the effect of different qualitative properties of flours on quality of Lavash breads during storage was evaluated. For this target, a variety of physical, chemical and rheological properties of flours and dough were specified. Mechanical properties, cellular structure and staling process of breads during storage were evaluated with texture analyzer, ultrasonic method, DSC device and SEM test. The results obtained from these tests were compared with the sensory evaluation results.

\section{Materials and Methods}

\section{Preparation of various kinds of flour with} different quality: Three kinds of Lavash flours with different quantities of protein content, wet gluten, zeleny volume, falling number, and damaged starch and with the same extraction rate (named strong flour, medium flour and weak flour) for preparation of Lavash bread according to Iran National Standard No. 
103 were prepared in Arddaran factory, located in Karaj, Iran. Some Lavash flour features in the standard include: ash (based on the dry matter): 0.850 to $1.125 \%$, moisture content: max. $14.2 \%$, protein (based on the dry matter): min. 11.5\%, wet gluten: min. 26 , zeleny sedimentation volume: $15-35 \mathrm{ml}$, and damaged starch: 1-8\%. To make strong flour, a mixture of $60 \%$ flour obtained from imported wheat (Australia and Russia) and 40\% flour made from Iran cities wheat (Khuzestan and Ilam) was used. For preparation of medium flour, we used a mixture of $40 \%$ wheat flour from imported wheat of the mentioned countries and 60\% flour from domestic wheat, and for production of weak flour, $100 \%$ of flour obtained from domestic wheat was used. These were used for experimental tests, and bread making. Baker's yeast powder was obtained from Fariman company, located in Mashhad, and salt was purchased from a local market.

Physical and chemical evaluation of wheat flour: Moisture content, ash, protein, zeleny sedimentation volume, wet gluten, gluten index, falling number, $\mathrm{pH}$ and damaged starch were determined in triplicate according to American Association of Cereal Chemists (AACC, 2000) procedures 16-44, 08-01, 46-12, 56-11, 56-81 and 38-11, respectively (32).

Rheological measurements of the dough: The viscoelastic behavior of dough samples was determined by an Alveograph (Chopin, France) following the standard method AACC 54-30 (AACC, 2000). Monitored parameters were tenacity or resistance to extension $(\mathrm{P})$, dough extensibility (L), swelling $(G), P / L$ (configuration ratio of curve), deformation energy (W) and index elasticity (Ie). Dough rheology during mixing was determined by a Consistograph (Chopin, France) following the standard method AACC 54-50 (AACC, 2000). Parameters recorded were: maximum pressure (PrMax), water absorption capacity (HYD2200, water required to yield dough consistency equivalent to $2200 \mathrm{mb}$ of pressure measured at constant hydratation), time (in sec) to reach maximum pressure (TprMax), time (in sec) for the pressure to rise above PrMax minus $20 \%$ or tolerance (Tol), the drop in pressure at $250 \mathrm{sec}$ from PrMax minus 20\% (D250), and the drop in pressure at $450 \mathrm{sec}$ from PrMax minus $20 \%$ (D450). Viscoelasticity of the sample blends was determined according to the following: flour is mixed with salted water, five dough samples are prepared, the samples are left to rest, and the dough samples swell under controlled test conditions. The Consistograph records the pressure during mixing, and from it deduces the water absorption of the flour. The curve and the associated calculated parameters are handled automatically by the integrated Alveolink (33).

Preparation of Lavash bread: Lavash bread was prepared without addition of any improvement in standard bakery and by professional baker, according to the code of practice of Lavash bread production (no. 58-10). Production method and the amount of raw materials used in producing different kinds of Lavash breads obtained from flours with different quality characteristics were considered identical. Wheat flours were baked using straight-dough method (approved method 10-10B AACC). The formula used to make Lavash breads is as follows: wheat flour, baker's yeast $(0.25 \%$ of flour weight), sodium chloride (1-2\% of flour weight) and the optimum amount of water calculated from water absorption, which was measured by Consistograph. The complete mixing of the dough samples was performed in a fork-type mixer at $35 \mathrm{rpm}$ within 10 minutes. The dough was fermented at $30^{\circ} \mathrm{C}$ and a relative humidity of $85 \%$ for 60 minutes in a fermentation cabinet divided into $190 \mathrm{~g}$ balls, and then the intermediate proofing was conducted for 10 minutes. The process was followed by flattening and final proofing for 5 minutes. The baking of Lavash bread was performed for 1 minute in a traditional oven at $330^{\circ} \mathrm{C}$. The baked loaves were then allowed to cool down to room temperature, packed in polypropylene bags and kept in room temperature for 7 days to determine the textural, microstructural, porosity and sensory changes of Lavash breads.

Texture analysis: The strength, firmness and stalling rate of Lavash breads were determined by Texture Analyzer (Brookfield, CT3, USA) according to AACC procedure 74-10 immediately, 48, 96 and 144 hours after baking for kinds of Lavash bread in triplicate. Penetration testing, which is in fact Normal Test (A Single Compression) of texture analyzer on Lavash bread slices with Dimensions $10 * 10 \mathrm{~cm}$ and single-layer thickness from central and lateral parts of 
bread, was determined. The bread samples were seated on the platform, and a circular probe (TA-5, D: $12 \mathrm{~mm}$ ) was loaded at the speed of $1 \mathrm{~mm} / \mathrm{s}$, target $10 \%$ and trigger load $0.05 \mathrm{~N}$ to puncture the breads. The curve was obtained to show the amount of power for penetration in bread. Textural properties of the samples were obtained from the curve.

Ultrasonic method to determine bread porosity and texture: A portable Ultrasonic Non-destructive Digital Indicating Tester (Proceq, Pundit Lab, UK) was used to generate a short (ve) voltage pulse (or spike). The voltage spike from the PUNDIT was connected to a transducer, which generated the ultrasonic signal that travelled through the sample. The ultrasonic pulse was detected at the other face of the sample with a similar transducer, which converted the transmitted ultrasonic signal back into an electromagnetic (EM) signal. This EM signal was then amplified at the receiver amplifier and displayed on the oscilloscope. The central frequency of the transducers used in the measurements was $54 \mathrm{kHz}$. The data were acquired using a computer-controlled digitizing oscilloscope. The digitized waveforms were transmitted directly to the hard disk of the computer for subsequent analysis. The amplitude of the ultrasonic pulse was directly measured from the peak height of the detected waveform in Volts. The velocity was measured by calculating the time taken for the signal to travel from one side of the sample to the other. The two transducers were bonded to the plate via a thin coupling layer (Ultragel, Diagnostic Sonar Ltd, Scotland). After the reference signal was acquired, the multilayer sample was placed between the two transducers, and the velocity and time of wave transition from samples were measured. All ultrasonic measurements were performed immediately, 48, 96 and 144 hours after baking for kinds of Lavash bread in triplicate at room temperature. Furthermore, using the results of the density and velocity of sound waves of each type of bread and the formula $\mathrm{E}=\rho \mathrm{V}^{2}$, the elastic modulus values of breads were calculated during storage time (11).

Evaluation of bread retrogradation by DSC: Gelatinization and retrogradation process of Lavash bread types were investigated by Different Scanning Calorimeter (DSC) device (PL-DSC,UK) with the temperature program $25-200^{\circ} \mathrm{C}$ and speed of temperature increase 10 degrees per minute. The DSC measurements were performed in the first, third and fifth days of storage for kinds of Lavash bread in triplicate. In endothermic curves of DSC, the main criteria for the interpretation of gelatinization and retro gradation of breads including the area under curve, onset point and peak top temperatures were studied.

Investigation of microstructure of breads crumb by SEM: After cutting the samples at specific dimensions and freeze drying of them, the microstructure and porosity of breads were evaluated using Scanning Electron Microscope (SEM) (LEO 44OI UK) in four magnifications (100, 250, 500 and 1000). The average pores' diameter and area of images with the same magnifications were determined by Microstructure Mesurment.exe software, and were compared to each other.

Sensory evaluation: The sensory evaluation of fresh breads was performed; then they were cooled down and packed in polyethylene bags immediately, 48, 96 and 144 hours after baking by ten experienced persons (5 men and 5 women aged 35 to 45 years) in temperature room. The attributes evaluated were shape and form, taste and aroma, lower and upper surface characteristics, void and porosity, chewability, and texture (firmness or softness). Sensory indexes of the bread samples were evaluated in a hedonic manner. Each attribute was scored from 0 (lowest) to 5 (highest). The following formula was used to calculate the overall score $(\mathrm{Q})$ of each bread sample:

$\mathrm{Q}=\Sigma(\mathrm{P} . \mathrm{G}) /(\Sigma \mathrm{G})$

Where, $P$ and $G$ are the sensory score and assessment coefficients of each attribute, respectively. The $G$ value for appearance (form and shape), lower surface specification, upper surface specification, void and porosity, chew-ability, texture (firmness and softness) and taste and aroma were 2, 1, 2, 3, 3, 4 and 5 , respectively $(34,35)$. Bread quality grading according to the panelist sensory scores is shown in Table 1. 
Table 1. Bread quality grading

\begin{tabular}{|c|c|}
\hline Score & Bread quality grading \\
\hline $4.50-5$ & So Good \\
\hline 4- 4.49 & Good \\
\hline $3-3.99$ & Satisfactory \\
\hline $2-2.99$ & Less Satisfactory \\
\hline $1-1.99$ & Not Satisfactory \\
\hline $0-0.99$ & Unacceptable \\
\hline
\end{tabular}

Statistical analysis: Three treatments (three kinds of Lavash flour) for flour assessments and 12 treatments (three types of Lavash bread and four levels of time) for bread assessments were considered. All determinations were made in triplicate, except the sensory test that was performed in ten repeats, and mean values were presented. The data were analyzed using SPSS version 21 (SPSS Inc., Chicago, IL). The analysis of variance (ANOVA) was performed as a two-factor factorial experiment in a completely randomized design to determine significant differences in each factor. A probability of $<0.05$ was used to establish statistical significance for main effects and interactions using Duncan's multiplecomparison test. Analysis of data obtained from the sensory evaluation was carried out using Friedman's statistical method. Pearrson's method was used to evaluate correlation coefficient between different methods with the significant difference at 0.01 level.

\section{Results}

\section{Physical and chemical tests results of Lavash flour:}

The chemical and physical results of Lavash flour types are presented in Table 2. Moisture content, ash percent and $\mathrm{pH}$ of flours had no significant differences; however, differences in protein content, wet gluten percent, gluten index, zeleny volume, falling number and damaged starch of Lavash flour types were detectable and affected the flour characteristics. The protein content, wet gluten, gluten index, zeleny volume and damaged starch percent in the strong flour were higher than in the medium flour, and were more in the medium flour than in the weak flour. There was a significant difference in the falling number results of three types of flour. The strong flour had less falling number than the medium flour, and the medium flour had lower falling number than the weak flour.

Table 2. The mean chemical and physical results of Lavash flour types

\begin{tabular}{|c|c|c|c|c|c|c|c|c|c|}
\hline $\begin{array}{l}\text { Properties } \\
\text { Types of } \\
\text { flour }\end{array}$ & Moisture \% & $\begin{array}{l}\text { Ash\% } \\
\text { (based on } \\
\text { the dry } \\
\text { matter) }\end{array}$ & $\begin{array}{c}\text { Protein \% } \\
\text { (based on the } \\
\text { dry matter) }\end{array}$ & Wet gluten \% & $\begin{array}{l}\text { Gluten } \\
\text { Index }\end{array}$ & $\begin{array}{c}\text { Zeleny } \\
\mathrm{ml}\end{array}$ & $\begin{array}{l}\text { Falling } \\
\text { number s }\end{array}$ & PH & $\begin{array}{l}\text { Damaged } \\
\text { starch \% }\end{array}$ \\
\hline Strong & $11.46 \pm 0.00^{\mathrm{a}}$ & $0.85 \pm 0.00^{a}$ & $13.26 \pm 0.01^{\mathrm{a}}$ & $30.45 \pm 0.00^{\mathrm{a}}$ & $90.02 \pm 0.01^{\mathrm{a}}$ & $32.00 \pm 0.00^{\mathrm{a}}$ & $355.00 \pm 0.57^{\mathrm{a}}$ & $6.09 \pm 0.03^{a}$ & $6.00 \pm 0.00^{a}$ \\
\hline Medium & $11.37 \pm 0.02^{\mathrm{b}}$ & $0.85 \pm 0.00^{\mathrm{a}}$ & $11.38 \pm 0.00^{\mathrm{b}}$ & $26.21 \pm 0.01^{\mathrm{b}}$ & $83.95 \pm 0.06^{b}$ & $23.50 \pm 0.28^{b}$ & $370.00 \pm 0.77^{b}$ & $6.03 \pm 0.02^{\mathrm{a}}$ & $2.20 \pm 0.11^{\mathrm{b}}$ \\
\hline Weak & $11.37 \pm 0.02^{b}$ & $0.85 \pm 0.01^{\mathrm{a}}$ & $9.73 \pm 0.02^{c}$ & $21.60 \pm 0.03^{c}$ & $76.06 \pm 0.00^{\mathrm{c}}$ & $17.00 \pm 0.02^{\mathrm{c}}$ & $385.00 \pm 0.08^{c}$ & $6.00 \pm 0.01^{\mathrm{a}}$ & $1.60 \pm 0.05^{\mathrm{c}}$ \\
\hline
\end{tabular}

Rheological measurements of the dough: The test results of Alveo and Consistograph on different types of Lavash flour are shown in Table 3. The average results of Alveograph, the tenacity or resistance to extension (P), dough extensibility (L), swelling $(\mathrm{G})$, $\mathrm{P} / \mathrm{L}$ (configuration ratio of curve), deformation energy (W) and index elasticity (Ie) of Lavash flour types had significant differences. The average results of Consistograph, the maximum pressure (PrMAX), water absorption (HYD), Tol and D 250 and D 450 of types of Lavash flours showed significant differences. The TPrMAX of strong and weak flours differed significantly to each other. According to the results, the strong flour's proportion to other flours had higher average values in $\mathrm{P}, \mathrm{P} / \mathrm{L}, \mathrm{W}$, Ie, PrMAX, HYD, TPrMAX and Tol but had lower mean results in L, G, D250 and D450.

Texture analysis: Average results of the texture analysis of Lavash bread types in storage days are shown in Table 4. The mean hardness of Lavash bread types showed significant differences on different storage days, and with increasing of storage time, the hardness value of breads increased. The average results of hardness in a variety of Lavash breads in the third and fifth days were significantly different, but there was no significant difference in 
the first and seventh days, respectively, between $\mathrm{B}$ and $\mathrm{C}$ Lavash breads and between A and B Lavash breads. The average results of hardness in the same storage days in Lavash B were less than in Lavash A and Lavash $\mathrm{C}$ until the fifth day but with longer storage time (seventh day), bread from the strong flour was softer than breads from the medium and weak flours, probably due to higher quality and quantity of protein in flour; in spite of being tougher at the beginning of production, it had less stiffness than other breads on the last day of storage. The mean results of Lavash breads' adhesive force and stringiness length did not show significant differences on different storage days. Also there was no significant difference between these features during the same storage days.

Table 3. Average results of the rheological test of Lavash flour types

\begin{tabular}{|c|c|c|c|c|c|c|c|c|c|c|c|c|}
\hline \multirow{3}{*}{$\begin{array}{l}\text { Properties } \\
\text { Types of } \\
\text { Flour } \\
\end{array}$} & \multicolumn{6}{|c|}{ Alveogram } & \multicolumn{6}{|c|}{ Consistogram } \\
\hline & \multirow[b]{2}{*}{$\begin{array}{c}\mathrm{P} \\
(\mathrm{mm})\end{array}$} & \multirow[b]{2}{*}{$\begin{array}{c}\mathrm{L} \\
(\mathrm{mm})\end{array}$} & \multirow[b]{2}{*}{$\mathrm{P} / \mathrm{L}$} & \multirow[b]{2}{*}{ G } & \multirow[b]{2}{*}{$\begin{array}{c}\mathrm{W} \\
\left(10^{-4} \mathrm{~J}\right)\end{array}$} & \multirow[b]{2}{*}{$\mathrm{Ie}$} & \multirow[b]{2}{*}{$\begin{array}{c}\text { PrMax } \\
(\mathrm{mb})\end{array}$} & \multicolumn{2}{|c|}{$\mathrm{AH}$} & \multicolumn{3}{|c|}{$\mathrm{CH}$} \\
\hline & & & & & & & & $\begin{array}{c}\text { HYD2 } \\
200 \\
(\%)\end{array}$ & $\begin{array}{c}\text { TPr } \\
\text { Max } \\
(\mathrm{s})\end{array}$ & $\begin{array}{l}\text { Tol } \\
\text { (s) }\end{array}$ & $\begin{array}{l}\text { D250 } \\
(\mathrm{mb})\end{array}$ & $\begin{array}{l}\text { D450 } \\
(\mathrm{mb})\end{array}$ \\
\hline Strong & $\begin{array}{l}90.00 \pm \\
3.46^{\mathrm{a}}\end{array}$ & $\begin{array}{c}77.33 \pm \\
1.20^{\mathrm{a}}\end{array}$ & $\begin{array}{l}1.26 \pm \\
0.04^{\mathrm{a}}\end{array}$ & $\begin{array}{c}18.56 \pm \\
0.20^{\mathrm{a}}\end{array}$ & $\begin{array}{c}228.33 \pm \\
2.20^{\mathrm{a}}\end{array}$ & $\begin{array}{l}49.16 \\
\pm 2.33^{\mathrm{a}}\end{array}$ & $\begin{array}{c}2584.00 \pm \\
11.37^{\mathrm{a}}\end{array}$ & $\begin{array}{c}55.43 \pm \\
0.06^{\mathrm{a}}\end{array}$ & $\begin{array}{l}108.00 \\
\pm 2.30^{\mathrm{a}}\end{array}$ & $\begin{array}{c}172.33 \pm \\
1.45^{\mathrm{a}}\end{array}$ & $\begin{array}{c}522.00 \pm \\
1.15^{\mathrm{a}}\end{array}$ & $\begin{array}{c}844.00 \pm \\
1.15^{\mathrm{a}}\end{array}$ \\
\hline Medium & $\begin{array}{l}77.67 \pm \\
1.45^{\mathrm{b}}\end{array}$ & $\begin{array}{c}83.00 \pm \\
0.57^{\mathrm{b}}\end{array}$ & $\begin{array}{l}0.93 \pm \\
0.02^{\mathrm{b}}\end{array}$ & $\begin{array}{c}20.40 \pm \\
0.01^{\mathrm{b}}\end{array}$ & $\begin{array}{c}167.33 \pm \\
0.88^{\mathrm{b}}\end{array}$ & $\begin{array}{c}38.40 \\
\pm 0.10^{\mathrm{b}}\end{array}$ & $\begin{array}{c}2446.33 \pm \\
8.41^{\mathrm{a}}\end{array}$ & $\begin{array}{c}54.37 \pm \\
0.03^{\mathrm{b}}\end{array}$ & $\begin{array}{l}104.00 \\
\pm 1.73^{\mathrm{ab}}\end{array}$ & $\begin{array}{l}142.33 \\
\pm 0.88^{\mathrm{b}}\end{array}$ & $\begin{array}{c}672.33 \pm \\
0.87^{\mathrm{b}}\end{array}$ & $\begin{array}{c}1012.00 \pm \\
2.18^{\mathrm{b}}\end{array}$ \\
\hline Weak & $\begin{array}{l}48.00 \pm \\
2.51^{\mathrm{c}}\end{array}$ & $\begin{array}{l}89.33 \pm \\
2.02^{\mathrm{c}}\end{array}$ & $\begin{array}{l}0.53 \pm \\
0.02^{\mathrm{c}}\end{array}$ & $\begin{array}{c}22.00 \pm \\
0.26^{\mathrm{c}}\end{array}$ & $\begin{array}{c}91.00 \pm \\
2.53^{\mathrm{c}}\end{array}$ & $\begin{array}{c}28.86 \\
\pm 1.46^{\mathrm{c}}\end{array}$ & $\begin{array}{c}2040.67 \pm \\
9.235^{\mathrm{b}}\end{array}$ & $\begin{array}{c}52.60 \pm \\
0.11^{\mathrm{c}}\end{array}$ & $\begin{array}{c}98.00 \pm \\
1.15^{\mathrm{b}}\end{array}$ & $\begin{array}{c}129.33 \pm \\
0.88^{\mathrm{b}}\end{array}$ & $\begin{array}{c}768.330 \pm \\
1.15^{\mathrm{c}}\end{array}$ & $\begin{array}{c}1109.00 \pm \\
1.15^{\mathrm{c}}\end{array}$ \\
\hline
\end{tabular}

Table 4. Average results of the texture analyzer test of Lavash bread types in storage days

\begin{tabular}{|c|c|c|c|c|}
\hline \multirow{2}{*}{ Types of Lavash Bread } & \multirow[t]{2}{*}{ Storage Time } & \multicolumn{3}{|c|}{ Textural Properties } \\
\hline & & Firmness N & Adhesive Force N & Stringiness Length $\mathrm{mm}$ \\
\hline \multirow{4}{*}{ Lavash A } & Day 1 & $14.74 \pm 0.28^{(\mathrm{a})(\mathrm{a})}$ & $1.81 \pm 0.44^{(\mathrm{a})(\mathrm{a})}$ & $0.53 \pm 0.12^{(\mathrm{a})(\mathrm{a})}$ \\
\hline & Day 3 & $22.18 \pm 0.07^{(\mathrm{b})(\mathrm{c})}$ & $1.63 \pm 0.05^{(\mathrm{a})(\mathrm{b})}$ & $0.49 \pm 0.11^{(\mathrm{a})(\mathrm{b})}$ \\
\hline & Day 5 & $25.08 \pm 0.17^{(\mathrm{c})(\mathrm{f})}$ & $1.52 \pm 0.19^{(\mathrm{a})(\mathrm{c})}$ & $0.37 \pm 0.10^{(\mathrm{a})(\mathrm{c})}$ \\
\hline & Day 7 & $27.34 \pm 0.20^{(\mathrm{d})(\mathrm{i})}$ & $1.47 \pm 0.71^{(\mathrm{a})(\mathrm{d})}$ & $0.35 \pm 0.08^{(\mathrm{a})(\mathrm{d})}$ \\
\hline \multirow{4}{*}{ Lavash B } & Day 1 & $12.70 \pm 0.09^{(\mathrm{e})(\mathrm{b})}$ & $1.54 \pm 0.24^{(\mathrm{b})(\mathrm{a})}$ & $0.40 \pm 0.13^{(\mathrm{b})(\mathrm{a})}$ \\
\hline & Day 3 & $18.50 \pm 0.34^{(\mathrm{f})(\mathrm{d})}$ & $1.45 \pm 0.18^{(\mathrm{b})(\mathrm{b})}$ & $0.37 \pm 0.16^{(\mathrm{b})(\mathrm{b})}$ \\
\hline & Day 5 & $21.44 \pm 0.26^{(\mathrm{g})(\mathrm{g})}$ & $1.37 \pm 0.46^{(\mathrm{b})(\mathrm{c})}$ & $0.31 \pm 0.08^{(\mathrm{b})(\mathrm{c})}$ \\
\hline & Day 7 & $29.18 \pm 0.23^{(\mathrm{h})(\mathrm{i})}$ & $1.35 \pm 0.55^{(\mathrm{b})(\mathrm{d})}$ & $0.27 \pm 0.12^{(\mathrm{b})(\mathrm{d})}$ \\
\hline \multirow{4}{*}{ Lavash $\mathrm{C}$} & Day 1 & $13.34 \pm 0.13^{(1)(b)}$ & $1.73 \pm 0.56^{(\mathrm{c})(\mathrm{a})}$ & $0.44 \pm 0.06^{(\mathrm{c})(\mathrm{a})}$ \\
\hline & Day 3 & $20.57 \pm 0.15^{(\mathrm{j})(\mathrm{e})}$ & $1.55 \pm 0.16^{(\mathrm{c})(\mathrm{b})}$ & $0.40 \pm 0.10^{(\mathrm{c})(\mathrm{b})}$ \\
\hline & Day 5 & $23.18 \pm 0.24^{(\mathrm{k})(\mathrm{h})}$ & $1.41 \pm 0.57^{(\mathrm{c})(\mathrm{c})}$ & $0.33 \pm 0.09^{(\mathrm{c})(\mathrm{c})}$ \\
\hline & Day 7 & $31.50 \pm 1.08^{(1)(\mathrm{j})}$ & $1.36 \pm 0.17^{(\mathrm{c})(\mathrm{d})}$ & $0.31 \pm 0.08^{(\mathrm{c})(\mathrm{d})}$ \\
\hline
\end{tabular}

The amounts listed in the table are mean \pm SD.

* Means within the same column having different letters are significantly different $(\mathrm{p}<0.05)$.

*The first letters in parentheses are for comparison of significant difference of Lavash breads separately at different days $(\mathrm{p}<0.05)$

*The second letters in parentheses are for comparison of significant difference of Lavash breads at the same days $(\mathrm{p}<0.05)$.

*Lavash A: Bread from strong flour, Lavash B: Bread from medium flour, Lavash C: Bread from weak flour 
Ultrasonic evaluation: Average results of the wave transition velocity, time, amplitude and elastic modulus of Lavash bread types in storage days ae shown in Figure 1. According to the results, mean velocity of ultrasonic wave's transition in the Lavash bread types showed significant differences on storage days. The mean time of ultrasonic wave's transition in types of breads was difference significantly, especially between the primary and last days of storage. The average amplitude of ultrasonic waves in Lavash A on the fifth and seventh days and in Lavash $\mathrm{B}$ and Lavash $\mathrm{C}$ separately on the first and third storage days had no significant difference. The mean amount of elastic modulus of Lavash bread types (that actually represents the textural changes and staling process during storage and the density and velocity of ultrasonic waves have direct effect on it) had no significant differences on the first and third days; however, it showed significant difference with each other in the other storage days. In all of the breads, with increased storage time, the mean velocity and amplitude of ultrasonic waves and elastic modulus of breads were increased, and time of wave transition was decreased.
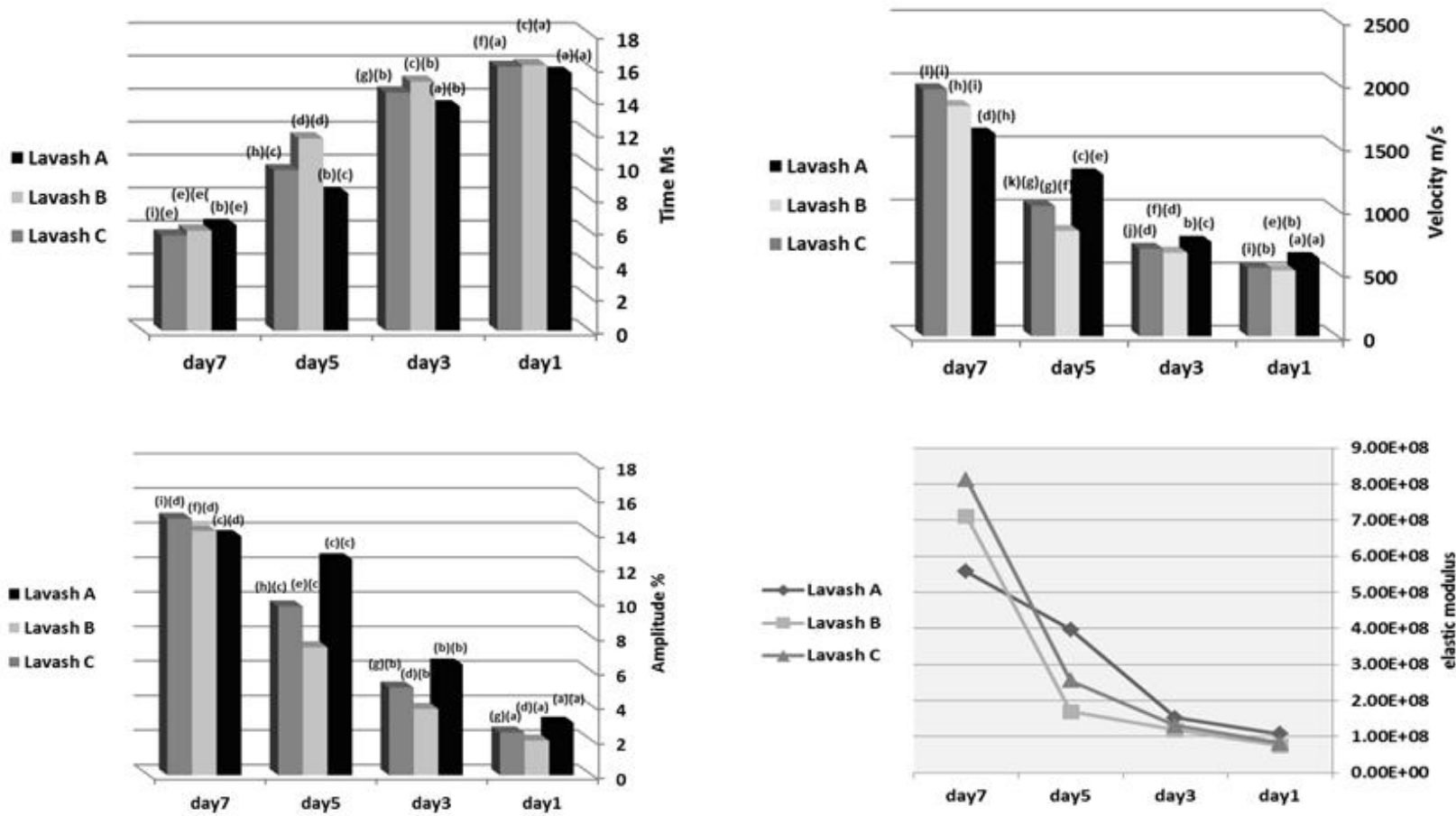

*The first letters in parentheses are for comparison of significant difference of Lavash breads separately at different days $(\mathrm{p}<0.05)$

$*$ The second letters in parentheses are for comparison of significant difference of Lavash breads at the same days $(\mathrm{p}<0.05)$

* Lavash A: Bread from strong flour, Lavash B: Bread from medium flour, Lavash C: Bread from weak flour

Figure 1. Average results of ultrasonic analysis of Lavash bread types in storage days

The mean velocity of ultrasonic waves in types of breads was significantly different on the same storage days but there were no significant difference between Lavash breads $\mathrm{B}$ and $\mathrm{C}$ on the first and third days of storage. Lavash B had lower wave transition velocity than Lavash $\mathrm{C}$, and Lavash $\mathrm{C}$ had lower wave transition velocity than Lavash A. The mean transmission time of ultrasonic wave in Lavash B was more than other breads only on the fifth day, and there was no significant difference between the types of breads on the same other days . There were no significant difference between the mean amplitude of ultrasonic waves of bread types during the same storage days. The average elastic modulus of Lavash bread types in the same storage days was significantly different only between Lavash bread A and the other breads. In this case, elastic modulus of Lavash B and Lavash $\mathrm{C}$ was less than that of Lavash $\mathrm{A}$ in different storage days. 
Evaluation of bread retro-gradation by DSC: Average results of onset Point ${ }^{\circ} \mathrm{C}$, peak Top ${ }^{\circ} \mathrm{C}$ and enthalpy of Lavash bread types in storage days are shown in Figure 2. The mean temperatures of onset Point and peak Top of Lavash breads were significant different between the first and fifth storage days. The mean values of the enthalpy of Lavash breads kept on different days were significantly different. In all types of Lavash breads, with increasing the storage time, the temperatures of onset Point and Peak Top and value of enthalpy were increased. In addition, the mean temperatures of onset Point and peak Top, and the average of enthalpy values were significantly different between Lavash A and Lavash B on the same storage days, and the mean temperatures and enthalpy values of Lavash A were more than Lavash $\mathrm{B}$ and Lavash $\mathrm{C}$ on the same storage days.

Investigation of microstructure and porosity of breads crumb by SEM: The images obtained by SEM (Figures 2-5) and comparison of the mean diameter and area of images pores (Table 5) with the same magnifications using Microstructure Mesurment.exe showed that the mean maximum diameter, minimum diameter, average diameter and area of images' pores of Lavash bread types were significantly different to each other. Also mean diameter and area of images pores and uniformity of them were higher in Lavash B than in Lavash C, and in Lavash $\mathrm{C}$ than in Lavash A.
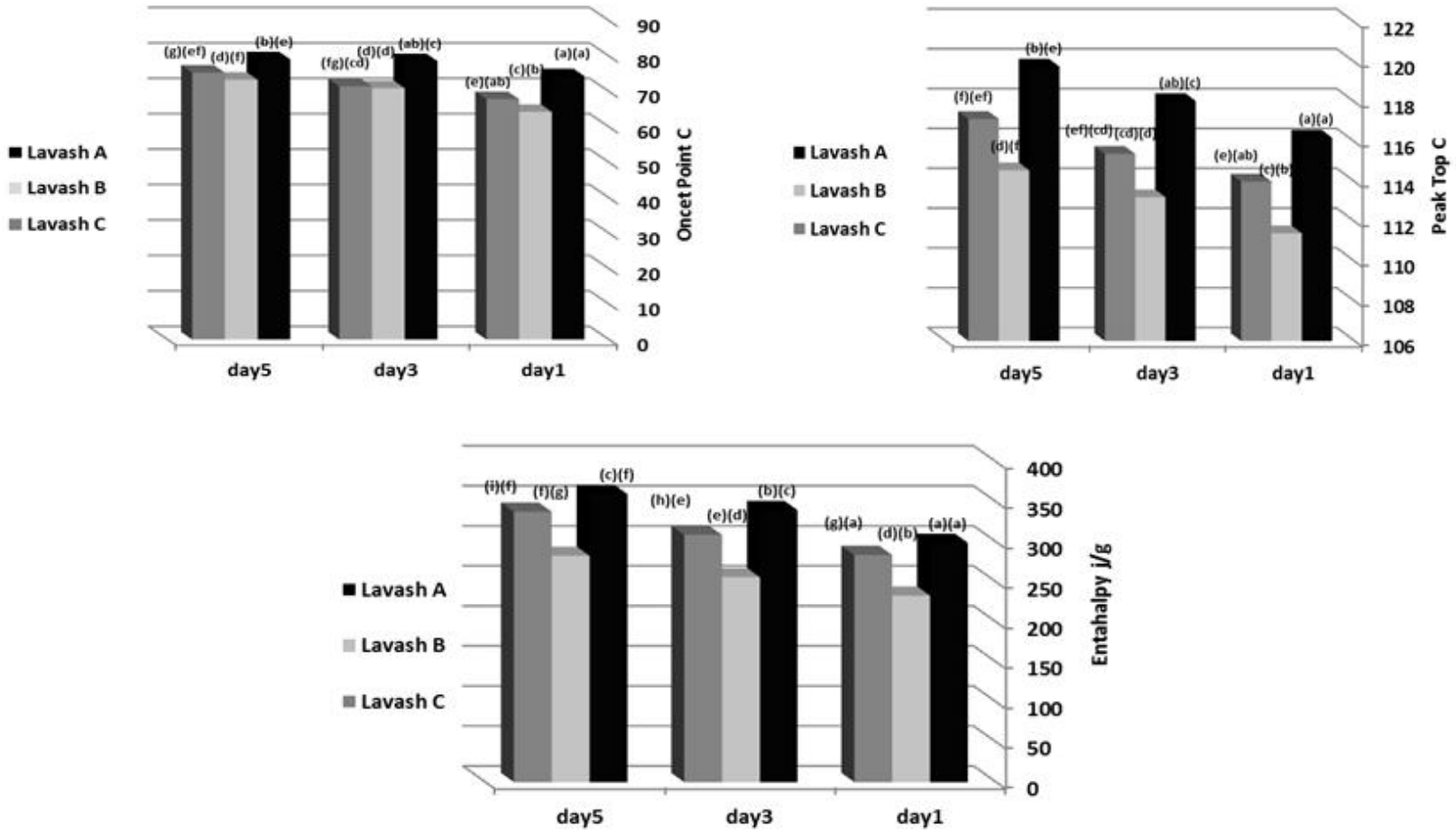

*The first letters in parentheses are for comparison of significant difference of Lavash breads separately at different days $(\mathrm{p}<0.05)$
$*$ The second letters in parentheses are for comparison of significant difference of Lavash breads at the same days $(p<0.05)$

* Lavash A: Bread from strong flour, Lavash B: Bread from medium flour, Lavash C: Bread from weak flour

Figure 2. Average results of DSC test of Lavash bread types in storage days

Table 5. Average results of the SEM test of Lavash bread types

\begin{tabular}{ccccc}
\hline properties & $\begin{array}{c}\text { Pores Max } \\
\text { Diameter }(\mu \mathrm{m})\end{array}$ & $\begin{array}{c}\text { Pores Min } \\
\text { Diameter }(\mu \mathrm{m})\end{array}$ & $\begin{array}{c}\text { Pores Average } \\
\text { Diameter }(\mu \mathrm{m})\end{array}$ & $\begin{array}{c}\text { Pores Average Area } \\
(\mu \mathrm{m})^{2}\end{array}$ \\
\hline Types of Lavash Bread & & & & \\
\hline Lavash A & $5.74 \pm 0.16^{\mathrm{a}}$ & $0.98 \pm 0.04^{\mathrm{a}}$ & $3.36 \pm 0.10^{\mathrm{a}}$ & $8.89 \pm 0.56^{\mathrm{a}}$ \\
Lavash B & $7.88 \pm 0.30^{\mathrm{b}}$ & $1.55 \pm 0.07^{\mathrm{b}}$ & $4.72 \pm 0.18^{\mathrm{b}}$ & $17.54 \pm 1.38^{\mathrm{b}}$ \\
Lavash C & $6.78 \pm 0.34^{\mathrm{c}}$ & $1.25 \pm 0.02^{\mathrm{c}}$ & $4.02 \pm 0.17^{\mathrm{c}}$ & $12.74 \pm 1.15^{\mathrm{c}}$ \\
\hline
\end{tabular}

The amounts listed in the table are mean \pm SD.

* Mean within the same column having different letters are significantly different $(\mathrm{p}<0.05)$.

* Lavash A: Bread from strong flour, Lavash B: Bread from medium flour, Lavash C: Bread from weak 

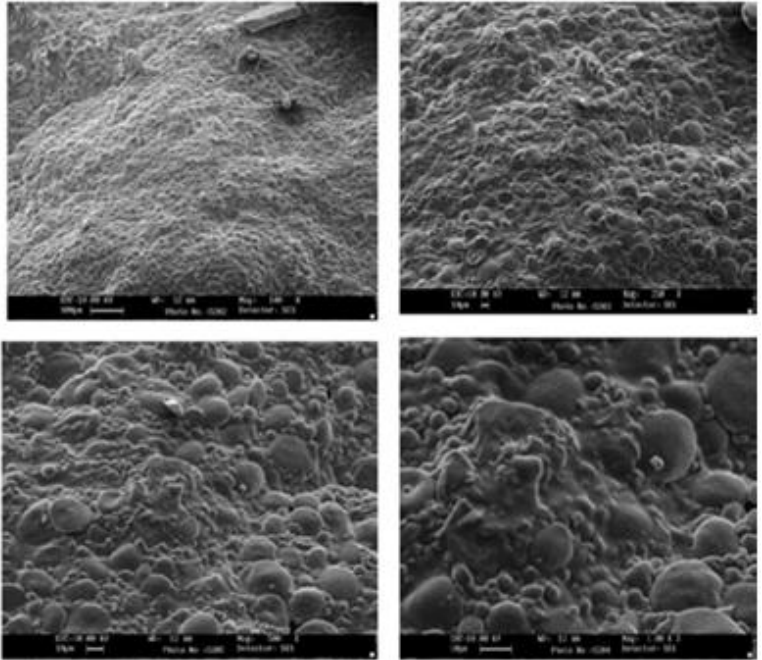

Figure 3. Lavash A crumb images, respectively, from the top and left to right in 4 magnifications $100,250,500 \& 1000$
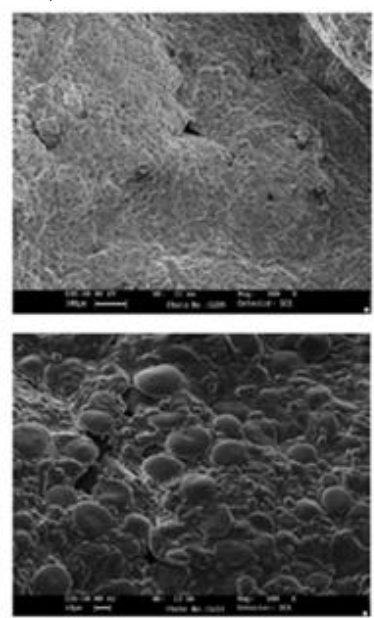
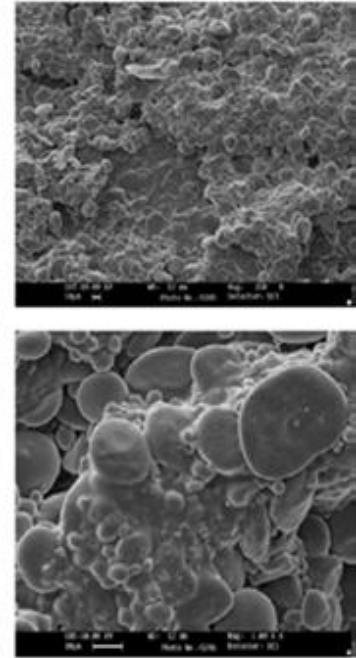

Figure 4. Lavash B crumb images, respectively, from the top and from from left to right in 4 magnifications $100,250,500 \& 1000$
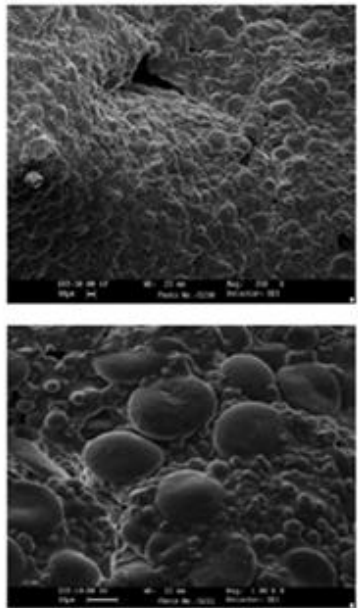

Figure 5. Lavash $\mathrm{C}$ crumb images, respectively, from the top and from left to right in 4 magnifications 100, $250,500 \& 1000$.

* Lavash A: Bread from strong flour, Lavash B: Bread from medium flour, Lavash C: Bread from weak flour

Sensory evaluation of Lavash breads: Average results of sensory evaluation of Lavash bread types in storage days are presented in Table 6. According to the statistical results, average points of form \& figure, properties under bread, properties on bread, porosity, chewiness, hardness, flavor $\&$ taste, and mean total point of Lavash bread types had separately significant difference in different storage days. There were also significant differences between the average scores of porosity, chewiness, hardness and total point of Lavash bread types during the same storage time; however, there was no significant difference between the average score of chewiness and hardness property of Lavash bread types on the seventh storage day. The average points of form and figure, properties under bread, properties on bread and flavor \& taste of types of Lavash bread showed significant difference until the fifth day but the score of these properties did not have significant difference on seventh day between Lavash A and Lavash C. During the storage days, especially until the fifth day, the average points of the mentioned features and the average total score of Lavash B were more than Lavash C, and these features were higher in Lavash $\mathrm{C}$ than in Lavash $\mathrm{A}$. The a verage scores of above features and the mean total score of Lavash A on the first day were good, on the third day were satisfactory, and on the fifth day were less satisfactory; on the seventh storage day, the average scores of form and figure, properties under bread, properties on bread, flavor \& taste and total 
point were not satisfactory and the mean points of chewiness, hardness and porosity were unacceptable. Mean points of the sensory properties of Lavash B were so good on the first day. On the third day, the average score of porosity was satisfactory and the mean points of other features were good. On the fifth day, the average points of form \& figure, properties under bread, properties on bread and flavor \& taste were satisfactory, the mean scores of other properties were less satisfactory, and on the seventh storage day, the average scores of all features were not satisfactory. On the first day, the average scores of form \& figure, properties under bread and properties on bread of Lavash $\mathrm{C}$ were so good and the mean points of other features were good. The mean points of sensory properties on the third, fifth and seventh days were satisfactory, less satisfactory and not satisfactory, respectively.

Table 6. Average results of the sensory evaluation of Lavash bread types in storage days

\begin{tabular}{|c|c|c|c|c|c|c|c|c|c|}
\hline \multirow{2}{*}{$\begin{array}{l}\text { Types of } \\
\text { Lavash } \\
\text { Bread }\end{array}$} & \multirow{2}{*}{$\begin{array}{l}\text { Storage } \\
\text { Time }\end{array}$} & & \multicolumn{7}{|c|}{ Sensory Properties } \\
\hline & & $\begin{array}{c}\text { Form and } \\
\text { figure }\end{array}$ & $\begin{array}{c}\text { Properties under } \\
\text { bread }\end{array}$ & $\begin{array}{c}\text { Properties on } \\
\text { bread }\end{array}$ & Porosity & Chewiness & Hardness & $\begin{array}{c}\text { Falavour and } \\
\text { taste }\end{array}$ & Total point \\
\hline \multirow{4}{*}{ Lavash A } & Day 1 & $4.32 \pm 0.02^{(\mathrm{a})(\mathrm{a})}$ & $4.31 \pm 0.02^{(\mathrm{a})(\mathbf{a})}$ & $4.31 \pm 0.03^{(\mathrm{a})(\mathrm{a})}$ & $4.23 \pm 0.02^{(\mathrm{a})(\mathrm{a})}$ & $4.25 \pm 0.02^{\text {(a)(a) }}$ & $4.23 \pm 0.02^{(a)(a)}$ & $4.22 \pm 0.03^{\text {(a)(a) }}$ & $4.25 \pm 0.01^{(\mathrm{a})(\mathrm{a})}$ \\
\hline & Day 3 & $3.75 \pm 0.01^{(b)(d)}$ & $3.75 \pm 0.01^{(b)(d)}$ & $3.74 \pm 0.01^{(\mathrm{b})(\mathrm{d})}$ & $3.60 \pm 0.05^{(\mathrm{b})(\mathrm{d})}$ & $3.71 \pm 0.02^{(b)(d)}$ & $3.68 \pm 0.04^{(b)(d)}$ & $3.83 \pm 0.01^{(\mathrm{b})(\mathrm{d})}$ & $3.72 \pm 0.03^{\text {(b)(d) }}$ \\
\hline & Day 5 & $2.80 \pm 0.03^{(\mathrm{c})(\mathrm{g})}$ & $2.80 \pm 0.03^{(\mathrm{c})(\mathbf{g})}$ & $2.86 \pm 0.04^{(\mathrm{c})(\mathrm{g})}$ & $2.54 \pm 0.03^{(\mathrm{c})(\mathrm{g})}$ & $2.34 \pm 0.04^{(\mathrm{c})(\mathrm{g})}$ & $2.34 \pm 0.03^{(\mathrm{c})(\mathrm{g})}$ & $2.63 \pm 0.08^{(\mathrm{c})(\mathrm{g})}$ & $2.55 \pm 0.01^{(\mathrm{c})(\mathrm{g})}$ \\
\hline & Day 7 & $1.16 \pm 0.03^{(\mathrm{d})(\mathbf{j})}$ & $1.07 \pm 0.05^{(\mathrm{d})(\mathbf{j})}$ & $1.08 \pm 0.03^{(\mathrm{d})(\mathbf{j})}$ & $0.90 \pm 0.01^{(\mathrm{d})(\mathfrak{j})}$ & $0.95 \pm 0.02^{(\mathrm{d})(\mathrm{j})}$ & $0.92 \pm 0.02^{(\mathrm{d})(\mathrm{j})}$ & $1.03 \pm 0.04^{(\mathrm{d})(\mathrm{j})}$ & $1.01 \pm 0.01^{(\mathrm{d})(\mathrm{j})}$ \\
\hline \multirow{4}{*}{ Lavash B } & Day 1 & $4.80 \pm 0.02^{(\mathrm{e})(\mathrm{b})}$ & $4.78 \pm 0.03^{(\mathrm{e})(\mathbf{b})}$ & $4.79 \pm 0.02^{(\mathrm{e}(\mathrm{b})}$ & $4.61 \pm 0.02^{(\mathrm{e})(\mathrm{b})}$ & $4.82 \pm 0.02^{(\mathrm{e})(\mathrm{b})}$ & $4.81 \pm 0.05^{(\mathrm{e})(\mathrm{b})}$ & $4.84 \pm 0.03^{(\mathrm{e})(\mathrm{b})}$ & $4.79 \pm 0.00^{(\mathrm{e})(\mathrm{b})}$ \\
\hline & Day 3 & $4.27 \pm 0.02^{(\mathrm{f})(\mathbf{e})}$ & $4.27 \pm 0.02^{(\mathrm{f})(\mathbf{e})}$ & $4.27 \pm 0.05^{(\mathrm{f})(\mathrm{e})}$ & $3.87 \pm 0.02^{(\mathrm{f})(\mathrm{e})}$ & $4.21 \pm 0.03^{(\mathrm{f})(\mathrm{e})}$ & $4.17 \pm 0.03^{(\mathrm{f})(\mathrm{e})}$ & $4.30 \pm 0.03^{(\mathrm{f})(\mathrm{e})}$ & $4.20 \pm 0.01^{(\mathrm{f})(\mathrm{e})}$ \\
\hline & Day 5 & $3.28 \pm 0.03^{(\mathrm{g})(\mathbf{h})}$ & $3.29 \pm 0.03^{(\mathrm{g})(\mathrm{h})}$ & $3.29 \pm 0.03^{(\mathrm{g})(\mathbf{h})}$ & $2.76 \pm 0.07^{(\mathrm{g})(\mathrm{h})}$ & $2.73 \pm 0.08^{(\mathrm{g})(\mathrm{h})}$ & $2.72 \pm 0.03^{(\mathrm{g})(\mathrm{h})}$ & $3.11 \pm 0.02^{(\mathrm{g})(\mathrm{h})}$ & $2.96 \pm 0.01^{(\mathrm{g})(\mathrm{h})}$ \\
\hline & Day 7 & $1.55 \pm 0.05^{(\mathrm{h})(\mathbf{k})}$ & $1.56 \pm 0.04^{(h)(\mathbf{k})}$ & $1.56 \pm 0.07^{(\mathrm{h})(\mathbf{k})}$ & $1.14 \pm 0.01^{(\mathrm{h})(\mathrm{k})}$ & $1.07 \pm 0.04^{(\mathrm{h})(\mathrm{j})}$ & $1.06 \pm 0.02^{(h)(j)}$ & $1.25 \pm 0.03^{(\mathrm{h})(\mathrm{k})}$ & $1.35 \pm 0.02^{(h)(k)}$ \\
\hline \multirow{4}{*}{ Lavash C } & Day 1 & $4.43 \pm 0.03^{(\mathrm{i})(\mathbf{c})}$ & $4.62 \pm 0.03^{(i)(\mathbf{c})}$ & $4.62 \pm 0.03^{(\mathrm{i})(\mathrm{c})}$ & $4.29 \pm 0.01^{(\mathrm{i})(\mathrm{c})}$ & $4.52 \pm 0.02^{(\mathrm{i})(\mathrm{c})}$ & $4.49 \pm 0.02^{(\mathrm{i})(\mathrm{c})}$ & $4.51 \pm 0.03^{(\mathrm{i})(\mathrm{c})}$ & $4.54 \pm 0.01^{(\mathrm{i})(\mathrm{c})}$ \\
\hline & Day 3 & $3.95 \pm 0.07^{(\mathbf{j})(\mathbf{f})}$ & $3.93 \pm 0.06^{(j)(\mathbf{f})}$ & $3.94 \pm 0.06^{(\mathbf{j})(\mathbf{f})}$ & $3.80 \pm 0.03^{(j)(f)}$ & $3.84 \pm 0.02^{(j)(f)}$ & $3.81 \pm 0.01^{(\mathrm{j})(\mathrm{f})}$ & $3.96 \pm 0.02^{(\mathrm{j})(\mathrm{f})}$ & $3.88 \pm 0.03^{(j)(f)}$ \\
\hline & Day 5 & $2.91 \pm 0.03^{(\mathrm{k})(\mathbf{i})}$ & $2.98 \pm 0.04^{(\mathrm{k})(\mathbf{i})}$ & $3.02 \pm 0.09^{(\mathrm{k})(\mathbf{i})}$ & $2.64 \pm 0.05^{(\mathrm{k})(\mathrm{i})}$ & $2.62 \pm 0.03^{(\mathrm{k})(\mathrm{i})}$ & $2.65 \pm 0.04^{(\mathrm{k})(\mathrm{i})}$ & $2.90 \pm 0.03^{(\mathrm{k})(\mathrm{i})}$ & $2.78 \pm 0.02^{(\mathrm{k})(\mathrm{i})}$ \\
\hline & Day 7 & $1.22 \pm 0.02^{(\mathrm{l})(\mathbf{j})}$ & $1.23 \pm 0.02^{(\mathrm{l})(\mathbf{j})}$ & $1.23 \pm 0.02^{(\mathrm{l})(\mathbf{j})}$ & $1.05 \pm 0.02^{\text {(l)(l) }}$ & $1.03 \pm 0.04^{(\mathrm{l})(\mathrm{j})}$ & $1.00 \pm 0.04^{(1)(j)}$ & $1.13 \pm 0.05^{(1)(\mathrm{jk})}$ & $1.14 \pm 0.02^{(\mathrm{l})(\mathrm{l})}$ \\
\hline
\end{tabular}

\section{Disc ussion}

The content of protein and wet gluten reflects the quantity of protein in flour types; gluten index and zeleny tests indicate the quality of protein in types of flours with different quality characteristics. Significant difference in the mentioned four characteristics of Lavash flour types is a fundamental factor for making the flours with different quality properties. Lower falling number and more activity of alpha-amylase in strong flour are probably due to differences in the type and nature of the wheat varieties used to produce flour with different quality characteristics. Notably, increased amylase activity but not beyond the normal range leads to further decomposition of starch and thus helps feed the yeast and fermentation of bread; therefore, volume and organoleptic properties of bread can be affected. More damaged starch percent in strong flour seems to be due to differences in the type and quality characteristics of the wheat used for production of flours, including the difference in the endosperm tissue, protein content and hardness of the wheat. The results of rheological measurements of the dough types were due to the direct effect of reducing of protein, wet gluten and zeleny volume and thus quality reduction of the gluten network in weak flour and also lower damaged starch percent than medium and strong flours. The results of dough rheology evaluation of this study confirmed the results of Callejo's research that evaluated wheat and rye dough rheological properties with different gluten quantity and quality by Alveo and Consistograph (33).

The results of texture analysis represented softer and more desirable texture of Lavash B than Lavasgh $\mathrm{A}$ and Lavash $\mathrm{C}$ due to flour qualitative characteristics of this type of bread to obtain dough with appropriate elasticity and excellent sheeting 
capability. Macritchie et al. (1991) reported that flat breads require shorter baking time as compared to pan breads, and consequently, doughs used for flat bread production must be expanded quickly during the short time of baking (36). These findings indicate that elastic doughs are not compatible with the rapid expansion of gases during the baking of flat breads. From another point of view, elastic doughs do not have ability to sheet. These properties adversely affect the structure of the final product (37). It was suggested that the sensitivity of flat breads' quality to change the elastic character of the dough is at the control of both protein quality and quantity, and there is a threshold of protein (quality and quantity) beyond which a rapid decline takes place in quality. Major question of interest for flat breads is to find the optimum balance for protein content and protein quality. Both of them, of course, have to be within certain limitations. Faergestad et al. (2000) showed that protein quality is also an important factor for flat breads as it is critical for the ability of the dough to retain proper shape during sheeting and shaping. This effect could not be compensated for by increasing the protein content (25).

The results of ultrasonic evaluation showed that by increasing the storage time, due to loss of breads' moisture, conversion of starch crystals to stable form and retro-gradation of them, staling of bread took place and porosity were reduced in the breads' crumb. With these changes, the elastic modulus of the breads was increased and the breads were tougher; so with increased solid and elastic mode of materials, velocity and amplitude of ultrasonic waves transition increase and time of ultrasonic wave transition decreases. Changes of velocity, amplitude and time of wave transmission in a variety of Lavash breads during storage are justified. The results revealed that bread from medium flour, after baking and during storage time, had less velocity of ultrasonic wave transition, more time wave transition, more moisture retention, less stiffness and less porosity reduction than breads from strong and weak flours. In general, these results confirm the results of texture analysis of Lavash bread types during storage time, and had significant correlation with the results of texture analyzer. For example, correlation efficient between the hardness value of Lavash B and the velocity of ultrasonic wave transition from it in the fifth storage day was 0.98 . Elmehdi et al. (2003) used ultrasonic techniques to study how the mechanical properties of bread crumb are affected by changing the size, concentration and shape of the crumb cells. The results showed that the sensitivity of ultrasonic waves changes the size and shape of crumb cells, and demonstrated the potential for using ultrasound as a tool for characterizing the mechanical and structural properties of bread crumb, and hence, for measuring some of the determining factors of bread quality (11). Ross et al. (2004) investigated the use of ultrasound and shear oscillatory tests to characterize the effect of mixing time on the rheological properties of dough. They found an agreement between the results obtained by conventional rheology and ultrasound measurements, which shows the potential of ultrasound as an on-line quality control technique for dough-based products (38). García-Álvarez et al. (2012) expressed the main advantages of the ultrasonic dough testing can be, among others, its low cost as well as hygienic and online performance (39).

According to the results of DSC test, increase in the enthalpy values, onset point and peak top tempratures of breads from the first day until the fifth day of storage implies the starch's retro- gradation that is one of the key factors of bread stalling. In fact, enthalpy values show the amount of energy required to melt the retro-gradated starch crystals. The results revealed that bread from medium flour, after baking and during storage, had less enthalpy values, and lower onset point and peak top temperatures, indicating more moisture retention, slower starch retrogradation, and stalling of this bread than breads from strong and weak flours. This matter is related to the qualitative characteristics of used flours including their protein quantity and quality. In this case, soft and poor Lavash bread from weak flour and stiff and rubbery Lavash bread from strong flour were effective on the stalling rate and shelf life of these breads. Lower enthalpy values for melting starch granoles in Lavash B shows slower stalling process, more desirable quality characterization and higher shelf life of this bread that was due to flour qualitative characteristics of this type of bread to obtain dough with appropriate elasticity and excellent sheeting capability, which retained more moisture. These 
results confirm the results of the texture analyzer and ultrasonic evaluation of Lavash bread types during storage time. For example, correlation efficient between enthalpy value and hardness value of Lavash A in the third sorage day was 0.95 , and the correlation efficient between the enthalpy value and the velocity of ultrasonic wave transition in Lavash A was 0.93 in the third day of storage. Giovanelli et al. (1997) studied effective factors on stalling and expressed that starch retrogradation is a key factor in the stalling process. They considered enthalpy values in DSC test as equal to the amount of retro-graded starch, and announced that the enthalpy value is the amount of energy required to melt starch crystals (40). Del Nobile (2003) reported that starch retrogradation may occur due to the growth of initial crystals that are not gelatinized or due to the creation and growth of new cores (41). Primo-Martin (2007) showed that gelatinization and retrogradation rate are higher in bread crumb than in bread crust (42).

The images obtained from SEM and the results of average diameter and area of images pores of Lavash bread types by microstructure mesurment.exe showed that because of the desirable elasticity threshold and suitable dough strength for production of Lavash flat bread, flour with medium quality properties had ability to form and maintain larger and more uniform pores in Lavash B than Lavash A, and Lavash C breads from strong and weak flours (that were stiff and rubbery or soft and poor and in both cases) retained less gas. In general, the microscopic structure of Lavash bread is more elegant than other breads, and the images obtained from the breads, especially Lavash B indicated that the gluten network surrounded the starch granules and a lot of starch granules swelled; however, they did not have opportunity to rupture and release their contents. Therefore, starch gelatinization in bread structure did not completely occur that was due to the limitation of Lavash bread baking opportunity than other breads. Notably, SEM test results confirmed the results of texture analyzer and ultrasonic method. There was statiscally significant positive correlation between the results of firmness and ultrasonic wave velocity but the pores' diameter and area in the bread images had statiscally significant negative correlation with the firmness and velocity of ultrasonic waves. The results of sensory evaluation showed that Lavash $\mathrm{B}$ from the medium flour had softer texture and better appearance characteristics, porosity and taste than Lavash breads made from the strong and weak flours. Lavash B showed more storage ability, and had slower staling trend during storage time; this depends directly on the quality features of flour, specially the gluten quantity and quality. These results confirm the results of texture analyzer about the hardness and chewiness features of breads.

Importantly, the results of mentioned tests (devices and sensory tests) had significant correlation to each other statiscally. For example, correlation efficient between the sensory properties (hardness and chewiness) and hardness value (TA) of Lavash $\mathrm{C}$ in the third sorage day was 0.99 , and correlation efficient between the sensory properties (prosity and hardness) and value and velocity of ultrasonic wave transition in Lavash $\mathrm{C}$ in the third day of storage was 0.94. Also, according to the quality grading of breads by experienced panelists during the storage, the staling of Lavash breads on the fifth day of storage shows that the quality characteristics of breads had significant defects and were less satisfactory. Thus, the results of other tests related to evaluation of texture and staling of breads such as TPA, ultrasonic and DSC in these days can be considered as indicators of bread staling phenomenon. Eventually, ultrasonic non-destructive method is recommended to use instead of other methods for assessing the texture, cell structure and elastic properties of bread after baking and during storage time. This method is fast, nondestructive and cheaper than other methods, and can be used during production.

\section{Acknowledgement}

The authors are grateful to the Science and Research Branch of Islamic Azad University for funding this work, and to the Arddaran Factory for supplying the flour.

\section{Financial disclosure}

The authors declared no financial interest.

\section{Funding/Support}

This study was supported by Science and Research Branch, Islamic Azad University, Tehran, Iran. 


\section{References}

1. Dobraszczyk BJ, Morgenstern MP. Rheology and the bread making process. J Cereal Sci 2003; 38: 229 245.

2. Decock P, Cappelle S. Bread technology and sourdough technology. Trends in Food Sci and Tech 2005; 16:113-120.

3. Arpita M, Datta AK. Bread baking - A review. J Food Eng 2008; 86: 465-474.

4. Stampfli L, Nersten B. Emulsifiers in bread making. Food Chem 1995; 52:353-360.

5. Zghal MC, Scanlon MG, Sapirstein HD. Effects of flour strength, baking absorption, and processing conditions on the structure and mechanical properties of bread crumb. J Cereal Chem 2001; 78:1-7.

6. Giannou V, Kessoglou V, Tzia C. Quality and safety characteristics of bread made from frozen dough. Trends in Food Sci and Tech 2003; 14: 99-108.

7. Keetels CJAM, Van Vliet T, Walstra P. Relationship between the sponge structure of starch bread and its mechanical properties. J Cereal Sci 1996; 24: 27-31.

8. Zhang J, Datta AK. Mathematical modeling of bread baking process. J Food Eng 2006; 75:78-89.

9. Caballero PA, Gomez M, Rosell CM. Improvement of dough rheology, bread quality and bread shelf life by enzymes combination. J Food Eng 2007; 81: 42-53.

10. Razmi-Rad E, Ghanbarzadeh B, Mousavi S M, Emamjomeh Z, Khazaei J. Prediction of rheological properties of Iranian bread dough from chemical composition of wheat flour by using artificial neural networks. J Food Eng 2007; 81: 728-734.

11. Elmehdi H M, Page JH, Scanlon MG. Using ultrasound to investigate the cellular structure of bread crumb. J Cereal Sci 2003; 38: 33-42.

12. Ribotta P, Bail A. Thermo-physical assessment of bread during staling. LWT - Food Sci and Tech 2007; 40: 879-884.

13. Goesaert H, Leman P, Bijttebier A, Delcour JA. Antifirming effects of starch degrading enzymes in bread crumb. J Agri and Food Chem 2009; 57: 23462355.

14. Gray JA, Bemiller JN. Bread staling: Molecular basis and control. Comprehensive Reviews in Food Sci and Food Safety 2003; 2: 1-21.

15. Fearn T, Russell PL. A kinetic-study of bread staling by differential scanning calorimetry - the effect of loaf specific volume. J the Sci of Food and Agri 1982; 33: 537-548.

16. Scanlon MG, Zghal MC. Bread properties and crumb structure. Food Research International 2001; 34:841864.
17. American Association of Cereal Chemists. AACC method 74-09: bread firmness by universal testing machine, 8th ed., Approved Methods of the American Association of Cereal Chemists 1983; II., Inc, St Paul.

18. Liu ZQ, Scanlon MG. Understanding and modeling the processing-mechanical property relationship of bread crumb assessed by indentation. J Cereal Chem 2002; 79:763-767.

19. Nussinovitch A, Steffens M, Chinachoti P, Peleg M. Effect of strain level and storage time on the recoverable work of compressed bread crumb. J Texture Studies 1992; 23: 13-24.

20. Piazza L, Masi P. Moisture redistribution throughout the bread loaf during staling and its effect on mechanical properties. J Cereal Chem 1995; 72: 320325 .

21. Chen P, Whitney LF, Peleg M. Some tensile characteristics of bread crumb. J Texture Studies 1994; 25: 299-310.

22. Persaud JN, Faubion JM, Ponte JG. Dynamic rheological properties of bread crumb. I. Effects of storage time, temperature, and position in the loaf. $\mathrm{J}$ Cereal Chem 1990; 67; 92-96.

23. Povey MJW, Mason TJ. Ultrasound in Food Processing. 1990; London, England: Blackie Academic \& Professional.

24. Alava JM, Sahi SS, Garcia -Alvarez A, Turo A, Chavez JA, Garcia MJ, Salazar J. Use of ultrasound for the determination of flour quality. Ultrasonics 2007; 46:270-276.

25- Faergestad EM, Molteberg EL, Magnus EM. Interrelationships of protein composition, protein level, baking process and the characteristics of hearth bread and pan bread. J Cereal Sci 2000; 31(3): 309-320.

26. Aamodt A, Magnus EM, Faergestad EM. Hearth bread characteristics: effect of protein quality, protein content, whole meal flour, proving time and their interactions. Cereal Chem 2005; 82: 290-301.

27. Lagrain B, Wilderjans E, Glorieux C, Delcoura JA. Role of gluten and starch in crumb structure and texture of fresh and stored straight-dough bread. Inside Food Symposium 2013; 4: 9-28.

28. Qarooni J. Flat Bread Technology, Andishmand Publishing 2004; PP 76-84.

29. Quail KJ. Effect of baking temperature/time conditions and dough thickness on Arabic bread quality. J Sci of Food and Agri 1990; 53(4): 527-540.

30. Toufeili I. The role of gluten proteins in the baking of Arabic bread. J Cereal Sci 1999; 30(3): 255-265. 
31. Salehifar M, Seyedein Ardebili M, Azizi MH. Effect of wheat flour protein variations on sensory attributes, texture and staling of Taftoon bread. Food Sci and Tech 2010; 30(3): 122-127.

32. American Association of Cereal Chemists (AACC). Approved methods of analysis of the AACC. 2000; 10. ed. St. Paul.

33. Callejo MJ, Bujeda C, Rodríguez G, Chaya C. Alveoconsistograph evaluation of rheological properties of rye doughs. Spanish. J Agri Research 2009; 7:638644

34. Ghanbari M, Farmni j. Influence of hydrocolloids on dough properties and quality of Barbari: An Iranian leavened flat bread. J Agri Sci and Tech 2013; 15: 545555 .

35. Bread Score Report, American Instititute of Baking (AIB). 1994; 1135 Fullerton Ave., Chicago, Illinois.

36. Macritchie F, Kasarda DD, Kuzmicky DD. Characterization of wheat protein fractions differing in contributions to breadmaking quality. Cereal Chemistry 1991; 68(2) 122-130.
37. Giovanelli G, Peri C, Borri V. Effects of baking temperature on crumb-staling kinetics. Cereal Chemistry 1997; 74(6):710-714.

38. Ross KA, Pyrak-Nolte LJ, Campanella OH. The use of ultrasound and shear oscillatory tests to characterize the effect of mixing time on the rheological properties of dough. Food Research International 2004; 37: 567-577.

39. García-Álvarez J, Rosell CM, García-Hernández MJ, Chávez JA, Turó A, Salazar A. Ultrasonic analysis to discriminate bread dough of different types of flour. IOP Conf. Series: Materials Sci and Engi 2012; 42, 012042 .

40. Giovanelli G, Peri C, Borri V. Effects of baking temperature on crumbstaling kinetics. J Cereal Chem 1997; 74: 710-714.

41. Del Nobile MA, Martoriello T, Mocci G, La Notle E. Modeling of starch retrogradation: Kinetic of durum wheat bread. J Food Eng 2003; 59: 123-128.

42. Primo-Martin C, Van Nicuwenhuijzen NH, Hamer RJ, Van Vliet T. Crystallinity changes in wheat starch during the bread making process: Starch cristallinity in the bread crust. J Cereal Sci 2007; 45: 219-226. 